\title{
A Simple and Economic Limewater-based Conversion of Spirostanol Saponins: Using Paridis Rhizoma as a case study
}

Lizhen Yu

Wannan Medical College

Fengjiao Bu

Fudan University

Xuebin Shen

Wannan Medical College

Ying Xiong

Wannan Medical College

Yong Fan

University of Copenhagen

Limin Liu ( $\square$ liulm2005@163.com )

Anhui University of Traditional Chinese Medicine

Sihui Nian ( $\nabla$ niansihui@126.com )

Wannan Medical College https://orcid.org/0000-0002-7330-5855

Research

Keywords: LCSS, Paridis Rhizoma; spirostanol saponin; conversion; processing

Posted Date: May 14th, 2020

DOI: https://doi.org/10.21203/rs.3.rs-26077/v1

License: (c) (i) This work is licensed under a Creative Commons Attribution 4.0 International License.

Read Full License 


\section{Abstract \\ Background}

Green and economic conversion of spirostanol saponins in the plant is considered as an attracting area in pharmaceutical applications. We aimed to provide a practical paradigm named limewater-based conversion of spirostanol saponins (LCSS), meanwhile, a widely-used traditional Chinese herbal medicine, Paridis Rhizoma (PR), was selected as a case study.

\section{Methods}

Based on single factor experiments, response surface methodology (RSM) using a Box-Behnken design (BBD) was employed to optimize processing time, limewater concentration and solvent volume to obtain a maximum total saponins yield from PR. H1299, A549 and HeLa cell lines was carried out to check pharmacological effect of Crude Paridis Rhizoma (CPR) and Processed Paridis Rhizoma (PPR), and the technology was reconfirmed by another herbal medicine, Anemarrhenae Rhizoma (AR).

\section{Results}

The optimal conditions were: processing time of $24 \mathrm{~h}$, limewater concentration of $0.12 \%$ limewater and solvent volume of $60 \mathrm{~mL} / 30 \mathrm{~g}$. Under these conditions, the contents of polyphyllin VII, polyphyllin II, dioscin, gracillin, and polyphyllin I had $1.131 \pm 0.448,1.835 \pm 0.479,1.430 \pm 0.550,1.761 \pm 0.571$ and $1.668 \pm 0.360$ times increasing in four batches of PR, which was responsible for the increasing of total spirostanol saponins (TSS) in PPR. In addition, the extracts of PPR exhibited stronger antitumor potential than that of CPR on H1299, A549 and HeLa cell lines based on MTT test and cell scratch test. The efficiency of proposed LCSS was then reconfirmed by Anemarrhenae Rhizome (AR), indicating its capacity in broader application.

\section{Conclusion}

This study depicted a LCSS strategy that may have great potential in achieving effective and economic improvement of spirostanol saponin accumulation in herbal medicines.

\section{Background}

Steroidal saponins, which are a type of defense compound in the plant kingdom, are exclusively distributed in the monocotyledonous families of Liliaceae, Dioscoreaceae, Alliaceae, Taccaceae, Asparagaceae, Dracaenaceae, and Agavaceae [1], and have been exploited for the production of lead compounds in drug discovery for their diverse pharmacological properties [2]. Steroidal saponins have 
been reported to exerts many biological activities, such as cardioprotective [3], antimicrobial [4], anticancer [5], anti-inflammatory [6], anti-diabetes [7], anti-oxidative effect [8], and so on.

$\mathrm{PR}$, known as Chonglou(ㅁ) in Chinese, is an well-established herbal medicine in China, often used to treat fevers, headaches, burns, wounds, and cancers [9]. Paris polyphylla Smith var. yunnanensis (Franch.) Hand.-Mazz and Paris polyphylla Smith var. chinensis (Franch.) Hara are the two legal species according to the CP 2015 edition [10], which is the main raw material of Chinese medicine including "Yunnan Baiyao" and "Gongxuening". Studies have shown that PR has diverse pharmacological effects including antitumor [11-13], antimicrobial [14], anthelmintic activities [15], promoting hemostasis [16], antifungal [17], and immuno-stimulating properties [18]. The major active components in PR are spirostanol saponins including polyphyllin VII, VI, I, II, which are as the markers for quality control of PR [19]. Besides the spirostanol glycosides, furostanol glycosides with an open side-chain at C-22 is another type of steroidal saponins in PR [20].

In order to increase potency and efficiency or to avoid side effects and toxicity, traditional Chinese herbs are often processed before prescription [21]. Limewater, as a traditional processing method, is employed to process some herbal medicines such as Pinelliae Rhizoma Praeparatum, Strychni Semen and Fritillaria anhuiensis [22-24]. In order to improve the utilization of PR, limewater was used to transform Colloid Paridis Rhizoma to Starchy Paridis Rhizoma [25], and we found that the content of spirostanol saponins, which are the quality marker of crude herbs and prepared slices, increased significantly after being processed, but the processing technology is not set up, and underlying mechanism was unclear. In this study, five typical spirostanol saponins including polyphyllin I, polyphyllin II, polyphyllin VII, gracillin and dioscin were selected to investigate the processing technology and the consequence of limewater-based conversion of spirostanol saponins (LCSS). Subsequently, their antitumor activity against H1299, A549 and HeLa cell lines was carried out to check pharmacological effect. In order to verify the processing technology, Anemarrhenae Rhizoma (AR), another herbal medicine rich in both furostanol and spirostanol saponins, was investigated. Thus, we set up a simple, green LCSS strategy, and these findings might provide paradigm for transformation of spirostanol steroidal compounds.

\section{Materials And Methods}

\section{Reagents and materials}

HPLC-grade acetonitrile was obtained from Tedia Company Inc. (Fairfield, OH,USA). Deionized water was purified using the Milli-Q system (Millipore, Bedford, MA,USA). All other chemicals were of analytical grade and commercially available. Standard compounds, including polyphyllin I, polyphyllin II and polyphyllin VII were supplied by China Food and Drug Inspection and Research Institute (Beijing, China), gracillin, dioscin, timosaponin BII (TS BII) and timosaponin AllI (TS AllI) were obtained from Chengdu Must Biotech Co., Ltd (Chengdu, China), the purity was higher than $98.0 \%$ which was determined by HPLC analysis, the chemical structure of polyphyllin I, polyphyllin II, polyphyllin VII, gracillin and dioscin were shown in figure S1. The crude Paridis Rhizoma was collected from Juhuacun Chinese herbal medicine 
market located in Kunming and Chinese medicinal herbs supplier in Simao, Yunnan Province, and Anemarrhenae Rhizoma was purchased from Bozhou County, Anhui Province, which was identified by Dr. Shuyun Bao from Wannan Medical College. The voucher specimen was deposited in School of Pharmacy, Wannan Medical College, Wuhu, Anhui Province.

H1299, A549 and HeLa cell lines were obtained from the Cell Bank of the Chinese Academy of Sciences (Shanghai, China). Cell lines were maintained in Dulbecco's modified Eagle medium (DMEM, Gibco) with $10 \%$ fetal bovine serum (FBS, Gibco) at $37^{\circ} \mathrm{C}$ in a humidified atmosphere with $5 \% \mathrm{CO}_{2}$.

\section{HPLC analysis for PR}

Quantitative analysis of Polyphyllin VII, Polyphyllin II, gracillin, dioscin and Polyphyllin I was implemented by HPLC on a Shimadzu Prominence LC-20AT liquid chromatographic system (Shimadzu Instruments Company, Japan) composed of quaternionic pumps, a SPD-20A UV/Visible detector, a SIL-20AC autosampler, CTO-20A column oven and LC solution software. A ZORBAX Eclipse XDB-C18 (4.6× $250 \mathrm{~mm}, 5 \mu \mathrm{m})$ and a ZORBAX Eclipse XDB $\mathrm{C}_{18}$ guard column $(10 \mathrm{~mm} \times 4 \mathrm{~mm}, 5 \mu \mathrm{m})$ were used. The mobile phase consisted of water $(A)$ and acetonitrile $(B)$ with the following gradient program: $0-8 \mathrm{~min}$, $32-34 \%$ of $B ; 8-15 \mathrm{~min}, 34-40 \%$ of $B ; 15-25 \mathrm{~min}, 40-40 \%$ of $B ; 25-27 \mathrm{~min}, 40-43 \%$ of $B ; 27-60 \mathrm{~min}$, $43-45 \%$ of $B, 60-65 \mathrm{~min}, 45-60 \%$ of $\mathrm{B}$. The column oven temperature was fixed at $30{ }^{\circ} \mathrm{C}$, and the online monitor wavelengths were set at $203 \mathrm{~nm}$. The flow rate was $1.0 \mathrm{~mL} / \mathrm{min}$ and the injection volume was 10 $\mu \mathrm{L}$. Calibration curves were established for the five saponins by plotting peak areas of standard solutions against their concentrations. The regression line were $Y=2655.5 X-7441.1\left(R^{2}=0.9998\right)$ for Polyphyllin VII, $Y=2994.9 X-17495\left(R^{2}=1.0000\right)$ for Polyphyllin II,Y = 3329.3X-11082 $\left(R^{2}=0.9998\right)$ for gracillin, $Y=$ $3328.3 X-17690\left(R^{2}=0.9999\right)$ for dioscin, and $Y=3155.1 X-18750\left(R^{2}=0.9999\right)$ for Polyphyllin $I$. The linear ranges were $8.80-440.00 \mu \mathrm{g} / \mathrm{mL}$ for polyphyllin VII, $18.24-912.00 \mu \mathrm{g} / \mathrm{mL}$ for polyphyllinll, $8.20-410.00 \mu \mathrm{g} / \mathrm{mL}$ for gracillin, $16.48-824.00 \mu \mathrm{g} / \mathrm{mL}$ for dioscin, and $19.72-986.00 \mu \mathrm{g} / \mathrm{mL}$ for Polyphyllin I.

\section{HPLC analysis for AR [26]}

Qualitative analysis of TS BII and TS All was executed according to the Shimadzu LC-20AT liquid chromatographic system, containing an ELSD. A Sepax $\mathrm{GP} \mathrm{C}_{18}$ reverse phase column $(250 \mathrm{~mm} \times 4.6 \mathrm{~mm}$, $5 \mu \mathrm{m})$ and a Shimadzu Inertsil ODS-SP $\mathrm{C}_{18}$ guard column $(10 \mathrm{~mm} \times 4 \mathrm{~mm}, 5 \mu \mathrm{m})$ were used. The mobile phase consisted of water (A, with $0.1 \%$ formic acid) and acetonitrile (B) with the following gradient program: $0-21 \mathrm{~min}, 23-24 \%$ of $B ; 21-24 \mathrm{~min}, 24-42 \%$ of $B ; 24-30 \mathrm{~min}, 42-55 \%$ of $B ; 30-43 \mathrm{~min}, 55-65 \%$ of $B ; 43-44 \mathrm{~min}, 65-90 \%$ of $B ; 44-49 \mathrm{~min}, 100-100 \%$ of $B$. The flow rate, the injection volume and the column oven temperature was $1.0 \mathrm{~mL} / \mathrm{min}, 10 \mu \mathrm{L}$ and $30^{\circ} \mathrm{C}$, respectively. The ELSD conditions were set as follows: drift tube temperature was $35^{\circ} \mathrm{C}$, gain value was 2 and carrier gas pressure was 350 bar.

\section{Preparation of CPR}


The crude materials were moistened with water and cut into $0.3 \mathrm{~cm}$ pieces. After dried in oven at $50{ }^{\circ} \mathrm{C}$, then was used as CPR in the following experiment.

\section{Single-factor experiments \\ Investigation of limewater concentration}

$60 \mathrm{~mL}$ of water, clarified limewater, $0.1 \%, 0.5 \%$ and $1 \%$ limewater were added into $30 \mathrm{~g}$ pieces of CPR (purchased from Simao) respectively, then the sample were processed for $24 \mathrm{~h}$, followed by removing the residual solvent and drying in oven at $50^{\circ} \mathrm{C}$.

\section{Investigation of processing time}

$60 \mathrm{~mL} 0.1 \%$ limewater was added into $30 \mathrm{~g}$ pieces of CPR (purchased from Simao), then the samples were processed for 6 h, 12 h, $24 \mathrm{~h}$ and $48 \mathrm{~h}$, respectively. Next, the residual solvent was discarded and the samples were dried in oven at $50^{\circ} \mathrm{C}$.

\section{Response surface methodology experiments}

Response surface method (RSM) was employed to optimize the conditions of processing technology. According to the results of single factor optimization, three variables including processing time, limewater concentration and solvent volume were selected, coded as $X_{1}-X_{3}$ and examined in three levels, then the Box-Behnken design includes 17 experiment runs were performed in random in order to evaluate the main effects of the factors. The factors, high and low levels, the obtained results are presented in Table 1.

\section{Scale-up experiment}

$500 \mathrm{~g}$ pieces of PR was immersed in $1000 \mathrm{~mL} 0.12 \%$ limewater for $24 \mathrm{~h}$, then the solvent was removed and PR was dried in oven at $50^{\circ} \mathrm{C}$. The treated PR was used as PPR.

\section{Preparation of sample solutions}

The CPR and PPR were grounded into powder and sieved (50 mesh). $0.5 \mathrm{~g}$ of sample powder was accurately weighed and transferred to a $50 \mathrm{~mL}$ glass-stoppered conical flask. $25 \mathrm{~mL} 80 \%$ ethanol $(\mathrm{v} / \mathrm{v})$ was added and the filled flask was weighed with a precision of $\pm 0.01 \mathrm{~g}$. The sample solution was sonicated with ultrasound for $40 \mathrm{~min}$, and cooled to room temperature. Then adjusted the flask to the initial weight by adding $80 \%$ ethanol $(\mathrm{v} / \mathrm{v})$ as needed, and the solution was filtered through a $0.22 \mu \mathrm{m}$ Millipore filter before injection for HPLC analysis.

\section{Preparation of extracts for pharmacological experiment in vitro}

About $200 \mathrm{~g}$ powder of CPR and PPR (purchased from Simao) were transferred to a $5000 \mathrm{~mL}$ roundbottomed flask equipped with a reflux condenser, followed by adding $3000 \mathrm{~mL} 80 \%$ ethanol $(\mathrm{v} / \mathrm{v})$ into the flask. The solutions were refluxed twice in heating jacket for $2 \mathrm{~h}$. The first and second filtrates were combined then concentrated using the vacuum rotary evaporator and lyophilized to powders. 


\section{MTT assay}

Inhibition effect of CPR and PPR on H1299, A549 and HeLa cell lines was evaluated by MTT assay. A total quantity of $1 \times 10^{4}$ cell lines were seeded in 96-well plates (Corning) and incubated overnight. Then, cell lines in each well were treated with different concentrations $(1,5,20,50,100 \mathrm{ng} / \mu \mathrm{L})$ of $\mathrm{CPR}$ or PPR, respectively, and the cell lines were further cultured for $24 \mathrm{~h}$. Next, $50 \mu \mathrm{L}$ of MTT reagent was added into each well according to the user manual of the reagent. The supernatants were then removed $4 \mathrm{~h}$ later, and $150 \mu \mathrm{L}$ of DMSO was added to dissolve formazan crystals. Absorbance at $550 \mathrm{~nm}$ was determined by a microplate reader.

\section{Cell scratch test}

H1299, A549 and HeLa cell lines were planted in 6-well plates (Corning) for scratch test. When the cell lines grew to a confluency of $90 \%$, a sterile pipette tip was used to create linear wounds on the surface of each well. Then the cell lines in plates were washed with PBS three times to remove the floating cell lines. Next, the cell lines were cultured in DMEM supplemented with 1\% FBS in an incubator. And different concentrations of CPR and PPR were added into each well, respectively. Cell migration was observed at 0 , $6,12,24 \mathrm{~h}$ by an inverted microscope. Image $\mathrm{J}$ was used to analyze the wound healing rate.

\section{Statistical Analysis}

Statistical analyses were conducted using SPSS 19.0 (IBM, Armonk, NY, USA), and statistical analysis of RSM was executed using Design Expert 8.06.1. The count data were presented as the mean \pm standard deviation. $p<0.05$ was considered statistical significance.

\section{Results}

\section{Analysis of HPLC}

Based on previous findings [27, 28], the chromatograms conditions of HPLC were optimized and established, the baseline resolution of the thirteen peaks was obtained and good peak shapes were observed without tailing (Fig. 1). In the chromatogram, peak 6, peak 9, peak 10, peak 11, and peak 12 were identified as polyphyllin VII, polyphyllin II, dioscin, gracillin, and polyphyllin I with authentic standards by comparing their retention times. Peak 6 was pennogenyl sanponin, and peak 9 , peak 10 , peak 11, and peak 12 were diosgenyl sanponins, and peak 1 , peak 2 , peak 3 and peak 4 were predicted to be prototype saponins according to the previous report [29].

\section{Single Factor Experiment}

The key factors of convert technology are limewater concentration and processing time, so in order to investigate these two conditions, a series of single factor experiments were carried out based on the contents of five saponins (total spirostanol saponins, TSS) in the pieces as the evaluation index. Keeping processing time at $24 \mathrm{~h}$, the concentration of limewater was investigated. The results showed that the 
contents of polyphyllin II, polyphyllin I, dioscin, gracillin and TSS ranked the highest in five groups when limewater concentration was $0.1 \%$, presenting $4.39 \pm 0.43,1.37 \pm 0.13,16.79 \pm 2.04,15.01 \pm 1.25$ and $38.74 \pm 0.66 \mathrm{mg} / \mathrm{g}$ (Table S1). Later on, the processing time was investigated while the limewater concentration was set at $0.1 \%$. We found that when processing time was less than $12 \mathrm{~h}$, the pieces can't be moistened thoroughly. When processing time was over $12 \mathrm{~h}$, the contents of polyphyllin II, polyphyllin I, dioscin, gracillina and the TSS peaked when processing time was $24 \mathrm{~h}$ (Table S2).

\section{Response Surface Methodology}

\section{Experimental Design and Results of BBD}

Based on single factor experiments, RSM using a BBD was employed to optimize processing time, limewater concentration and solvent volume to obtain a maximum yield of TSS including five known polyphyllins. As seen in Table 1, the results showed that the yields of TSS ranged from $15.12 \mathrm{mg} / \mathrm{g}$ to $20.06 \mathrm{mg} / \mathrm{g}$.

\section{Fitting the Model}

The analysis of variance (ANOVA), goodness-of-fit and the adequacy of the regression model were summarized in Table 2. In this model, the second-order polynomial model for the yield of TSS was statistically significant with a small model $p$-value $(p<0.0001)$ and satisfactory coefficient of determination $\left(R^{2}=0.9721\right)$. In this case, interaction parameters $\left(X_{1} X_{3}, X_{2} X_{3}\right)$ and quadratic parameters

$\left(X_{1}{ }^{2}, X_{2}{ }^{2}, X_{3}{ }^{2}\right)$ were significant at the level of $p<0.01$, the linear parameter of $X_{2}$ was significant at the level of $p<0.05$. The "Lack of Fit-Value" of the model is not significant with a p-value of 0.4725 . The significant regression and non-significant lack of fit indicated that the regression equation is adequate to represent the actual relationship between the response values $(Y)$ and three independent variables. The quadratic regression equation was obtained as follows Eq. (1):

$Y=4.374+0.824 * X_{1}+23.729 * X_{2}+0.129 * X_{3}+0.356 * X_{1} X_{2}-0.003 * X_{1} X_{3}+0.661 * X_{2} X_{3}-0.014 * X_{1}{ }^{2}-$ $300.400 * X_{1}^{2}-0.001 * X_{1}^{2}(1)$

\section{Analysis of Response Surfaces}

Response surface plots were shown in Figure S2. The interaction between various factors can be seen directly from the response surfaces plots. Figure S2A shows the effect of the interaction of processing time and limewater concentration on the yield of TSS at a fixed solvent volume of $60 \mathrm{~mL}$. An increase of limewater concentration $\left(X_{2}\right)$ resulted in an increase of yield of TSS to a maximum at a certain level, while an increase of processing time $\left(X_{1}\right)$ resulted in an initial increase of yield of TSS and then decreased as the processing time continued to increase. Figure S2B shows the effect of the interaction of the volume and processing time on the yield of TSS at a fixed limewater concentration of $0.1 \%$. It could be observed that the volume and processing time resulted in similar effects on yield of TSS as in Figure S2A. Figure S2C shows the effect of the interaction of volume and limewater concentration on the yield of TSS at a fixed processing time of $24 \mathrm{~h}$. It could be observed that both volume and limewater 
concentration demonstrated a positive influence on the yield of TSS. The combination of the analysis of variance (ANOVA) (Table 2) and response surfaces (Figure S2) indicated that the interaction effect between processing time and solvent volume interaction parameters $\left(X_{1} X_{3}\right)$, and limewater concentration and solvent volume $\left(X_{2} X_{3}\right)$ were statistically significant, but the interaction effect between processing time and limewater concentration $\left(X_{1} X_{2}\right)$ was non-significant. Furthermore, it was concluded that the effect of limewater concentration was more significant than solvent volume and processing time on the content of TSS.

\section{Optimization of LCSS}

Optimized conditions for the system were processing time $24.48 \mathrm{~h}, 0.12 \%$ limewter concentration and solvent volume $59.99 \mathrm{~mL}$, aimed to maximize the yield of TSS. Considering the operability, the optimal conditions were slightly modified as follows: extraction time, $24.5 \mathrm{~h}$; limewter concentration, $0.12 \%$; and solvent volume, $60 \mathrm{~mL}$. To confirm the suitability of the model equation, three confirmation experiments were conducted under the optimized conditions. Under these conditions the experimental the yield of TSS was $19.69 \pm 0.14 \mathrm{mg} / \mathrm{g}$, which matched well with the predicted values of $19.75 \mathrm{mg} / \mathrm{g}$. This confirmed that the model was adequate for optimization of the LCSS.

\section{Verification of LCSS}

Based on above optimized parameters, $500 \mathrm{~g}$ of four batches of PR collected from Yunnan Province were verified under the conditions of $0.12 \%$ limewater, processing time of $24 \mathrm{~h}$ and solvent volume of $1000 \mathrm{~mL}$. The results showed that the content of TSS in PPR increased distinctly, from $16.65 \pm 0.48 \mathrm{mg} / \mathrm{g}$ to 35.97 $\pm 0.96 \mathrm{mg} / \mathrm{g}$ in batch one, from $21.63 \pm 0.24 \mathrm{mg} / \mathrm{g}$ to $30.05 \pm 0.32 \mathrm{mg} / \mathrm{g}$ in batch two, from $22.02 \pm$ $0.27 \mathrm{mg} / \mathrm{g}$ to $40.72 \pm 0.57 \mathrm{mg} / \mathrm{g}$ in batch three, and from $16.39 \pm 0.23 \mathrm{mg} / \mathrm{g}$ to $20.24 \pm 0.68 \mathrm{mg} / \mathrm{g}$ in batch four (Table 3). The ratio of areas of peak 1, 2, 3, 4, 5, 7, 8, 13 and the content of five known polyphyllins in PPR and CPR were calculate to investigate the content variation of compounds. The average ratios of peak $1,2,3,4,5$ and 7 in four batches of PPR/CPR were less than 1, while that of polyphyllin VII, polyphyllin II, dioscin, gracillin, and polyphyllin I were $1.131 \pm 0.448,1.835 \pm 0.479,1.430 \pm 0.550,1.761 \pm$ 0.571 and $1.668 \pm 0.360$ (Fig. 2), indicating that spirostanol saponins can be converted after limewater processing.

\section{MTT test}

To evaluate LCSS, the cytotoxicity of CPR and PPR on H1299, A549 and HeLa cell lines were carried out. We calculated the inhibition rate by the OD value of cell lines treated by different concentrations of CPR and PPR comparing with control group using MTT assay. The results revealed that both CPR and PPR can significantly inhibit the activity of three tumor cell lines in a dose-dependent manner. What's more, PPR exhibited a stronger inhibition than CPR at the same concentration in most groups (Fig. 3).

\section{Cell scratch test}

Cell scratch test is usually used in studies to find out the effect of drugs on the ability of migration of cell lines in vitro. We compared the migration ability of H1299, A549 and HeLa cell lines treated with CPR and 
PPR, respectively. The results illustrated that the migration distance of $\mathrm{H} 1299$, A549 and HeLa cell lines treated with CPR and PPR was considerably less than that of control cell lines after $24 \mathrm{~h}$ culture, suggesting that both samples can suppress the metastasis of three tumor cell lines. Furthermore, the migration ability of cell lines treated with PPR were significantly decreased than cell lines treated with CPR on the H1299 cell lines at the concentration of $10 \mathrm{ng} / \mu \mathrm{L}$ and on the HeLa cell lines at the concentration of $10 \mathrm{ng} / \mu \mathrm{L}$ and $20 \mathrm{ng} / \mu \mathrm{L}(p<0.05)$, implying that PPR presented stronger inhibitory activity of migration on all tumor cell lines than CPR (Fig. 4).

\section{Discussion}

As a comprehensive mathematical and statistical method, RSM has been applied to optimize multiple factors [30-32], and BBD is a traditional method that is used in the experimental design [33, 34]. In the article, the factors of limewater concentration, processing time and solvent volume were listed to optimize the technology of LCSS based on BBD. In order to lessen the error of contents in sample, the crude materials was cut into $0.3 \mathrm{~cm}$ pieces, and $30 \mathrm{~g}$ of sample was employed in single processing experiment. When the solvent volume was $45 \mathrm{~mL}$, the sample was moistened felicitously, so the levels of solvent volume were selected as $30 \mathrm{~mL}, 60 \mathrm{~mL}$ and $90 \mathrm{~mL}$, considering that excessive solvent caused the composition dissolving out.

Steroidal saponins are classified into two subfamilies, spirostanol type saponins and furostanol type saponins [35], there are furostanol and corresponding spirostanol type compounds simultaneously in plants [36], and furostanol saponins can be converted into spirostanol form when catalyzing by furostanol glycoside 26-0- $\beta$-glucosidase [37, 38]. In the study, the contents of TSS increased after limewater processing, and the increasing amount of polyphyllin II, gracillin, dioscin, and polyphyllin I are responsible for the increasing of TSS. PR also contains these two types of compounds [39,40], the transformation mechanism was speculated that C-22 hydroxy furostanol saponins were converted to the corresponding spirostanol saponins by deglycosylation reactions, cleavage of 26 aglycone bonds and Fcyclization after limewater processing, in accordance with that the area of peak 1, peak 2, peak 3 and peak 4 decreased in the HPLC chromatograms of four batches PR. In order to demonstrate the hypothesis, we selected Anemarrhenae Rhizome (AR), another herbal medicine comprising furostanol saponin of timosaponin BII (TS BII) and spirostanol form of timosaponin Alll (TS Alll), to verify the LCSS based on the optimized parameters. After processing, the area of TS Bll peak decreased dramatically, from 837823 to 256393 , while the area of TS All increased markedly, from 8455 to 1397972 (Fig. 5a). Accordingly, the transformation from furostanol saponins to spirostanol form was probably the important mechanism in limewater processing (Fig. 5b). The amount of spirostanol saponins fluctuated after processing in three batches of PR, which may be related to the content of corresponding precursor saponins.

The compounds of polyphyllin I, polyphyllin II, gracillin and dioscin, which are quality control markers of PR, present excellent antitumor activity in recent reports [41-46]. In this work, the content of polyphyllin I, polyphyllin II, gracillin and dioscin increased significantly in PR after processing, showing consistence 
with the fact that PPR exhibited a stronger effect on tumor cell lines than CPR in both MTT assay and scratch test. Taken together, the stronger anticancer effect of PPR can be attributed the increased content of spirostanol saponins, suggesting that it might be useful for quality promotion of PR.

\section{Conclusion}

The processing technology of LCSS was established, with the content of spirostanol saponins increased significantly in the PPR. The mechanism of transformation is assumed that furostanol type saponins is converted into corresponding spirostanol saponin via deglycosylation in LCSS, which was reconfirmed by AR. The PPR had a notable advantage of higher content of active ingredients and stronger antitumor activity, meaning that the application of LCSS improved the quality of PR, and represented a more valuable alternative to CPR. Thus, a simple, economic and effective LCSS strategy of spirosteranol saponins was set up in raw materials based on activity evaluation and constituent analysis. The results of this research might provide paradigm for elucidating the processing mechanism of $P R$, and also will expand its application in pharmaceutical industry for the preparation of other spirostanol steroid saponin in herbal materials.

\section{Abbreviations}

LCSS, limewater-based conversion of spirostanol saponins; PR, Paridis Rhizoma; PPR, Processed Paridis Rhizoma; CPR, Crude Paridis Rhizoma; Total spirostanol saponins, TSS; RSM, Response surface methodology; BBD, Box-Behnken design; AR, Anemarrhenae Rhizome; TS Bll, timosaponin Bll; TS Alll, timosaponin Alll.

\section{Declarations}

\section{Authors' Contributions}

SN, LL and FB designed the experiments. $L Y, L L$ and $X Y$ performed the experiments. $X S$ and $F B$ analyzed the data. LY and FB wrote the manuscript. XS, LL, YF and SN discussed the results and revised the final manuscript. All authors read and approved the final manuscript.

\section{Competing interests}

The authors declare that they have no competing interests.

\section{Funding}

This work was financially supported by Foundation for Distinguished Young Talents in Higher Education of Anhui Province (2013SQRL057ZD), Natural Science Foundation of the Higher Education Institutions of Anhui Province区KJ2017A258囚囚Key Science and Technology Program of Anhui Province 
(201904a07020106), Key Science and Technology Program of Wuhu City (2019yf47), and Foundation of the Academic and technical leaders in Wannan Medical College reserve candidates.

\section{Acknowledgements}

The authors would like to thank Dr. Shuyun Bao for providing the identification of rude materials.

\section{Availability of data and materials}

All data used to support the findings of this study are available from the corresponding author upon request.

\section{Ethics approval and consent to participate}

Not applicable.

\section{Consent for publication}

Not applicable.

\section{References}

1. Sparg SG, Light ME, van Staden J. Biological activities and distribution of plant saponins. J Ethnopharmacol. 2004;94:219-43.

2. Yang J, Wang P, Wu W, Zhao Y, Idehen E, Sang S. Steroidal Saponins in Oat Bran. J Agric Food Chem. 2016;64:1549-56.

3. Jayachandran KS, Vasanthi AH, Gurusamy N. Steroidal Saponin Diosgenin from Dioscorea bulbifera Protects Cardiac Cells from Hypoxia-reoxygenation Injury Through Modulation of Pro-survival and Pro-death Molecules. Pharmacogn Mag. 2016;12:14-20.

4. Wang MY, Peng Y, Peng CS, Qu JY, Li XB. The bioassay-guided isolation of antifungal saponins from Hosta plantaginea leaves. J Asian Nat Prod Res. 2018;20:501-9.

5. Bhuvanalakshmi G, Rangappa KS, Dharmarajan A, Sethi G, Kumar AP, Warrier S. Breast Cancer StemLike Cells Are Inhibited by Diosgenin, a Steroidal Saponin, by the Attenuation of the Wnt beta-Catenin Signaling via the Wnt Antagonist Secreted Frizzled Related Protein-4. Front Pharmacol. 2017;8:124.

6. Kitahiro Y, Koike A, Sonoki A, Muto M, Ozaki K, Shibano M. Anti-inflammatory activities of Ophiopogonis Radix on hydrogen peroxide-induced cellular senescence of normal human dermal fibroblasts. J Nat Med. 2018;72:905-14.

7. Chen MH, Chen XJ, Wang M, Lin LG, Wang YT. Ophiopogon japonicus-A phytochemical, ethnomedicinal and pharmacological review. J Ethnopharmacol. 2016;181:193-213.

8. Wu AG, Teng JF, Wong VK, Zhou XG, Qiu WQ, Tang Y, Wu JM, Xiong R, Pan R, Wang YL, et al. Novel steroidal saponin isolated from Trillium tschonoskii maxim. exhibits anti-oxidative effect via 
autophagy induction in cellular and Caenorhabditis elegans models. Phytomedicine. 2019;65:153088.

9. Wang CW, Tai CJ, Choong CY, Lin YC, Lee BH, Shi YC, Tai CJ. Aqueous Extract of Paris polyphylla (AEPP) Inhibits Ovarian Cancer via Suppression of Peroxisome Proliferator-Activated ReceptorGamma Coactivator (PGC)-1alpha. Molecules. 2016;21:727. Doi:10.3390/molecules21060727.

10. National Pharmacopoeia Commission. Chinese Pharmacopoeia. Pharmacopoeia of the People's Republic of China 2015 ed.; China Medico Pharmaceutical Science \& Technology Publishing House: Beijing, China, 2015; Volume I, p. 260.

11. Guo Y, Liu Z, Li K, Cao G, Sun C, Cheng G, Zhang D, Peng W, Liu J, Qi Y, et al. Paris Polyphylla-Derived Saponins Inhibit Growth of Bladder Cancer Cells by Inducing Mutant P53 Degradation While UpRegulating CDKN1A Expression. Curr Urol. 2018;11:131-8.

12. Yao N, Ren K, Wang Y, Jin Q, Lu X, Lu Y, Jiang C, Zhang D, Lu J, Wang C, et al. Paris polyphylla Suppresses Proliferation and Vasculogenic Mimicry of Human Osteosarcoma Cells and Inhibits Tumor Growth In Vivo. Am J Chinese med. 2017;45:575-98.

13. Tan GX, Wang XN, Tang YY, Cen WJ, Li ZH, Wang GC, Jiang JW, Wang XC. PP-22 promotes autophagy and apoptosis in the nasopharyngeal carcinoma cell line CNE-2 by inducing endoplasmic reticulum stress, downregulating STAT3 signaling, and modulating the MAPK pathway. J Cell Physiol. 2019;234:2618-30.

14. Qin XJ, Sun DJ, Ni W, Chen CX, Hua Y, He L, Liu HY. Steroidal saponins with antimicrobial activity from stems and leaves of Paris polyphylla var. yunnanensis. Steroids. 2012;77:1242-8.

15. Wang GX, Han J, Zhao LW, Jiang DX, Liu YT, Liu XL. Anthelmintic activity of steroidal saponins from Paris polyphylla. Phytomedicine. 2010;17:1102-5.

16. Fu YL, Yu ZY, Tang XM, Zhao Y, Yuan XL, Wang S, Ma BP, Cong YW. Pennogenin glycosides with a spirostanol structure are strong platelet agonists: structural requirement for activity and mode of platelet agonist synergism. J Thromb Haemost. 2008;6:524-33.

17. Deng D, Lauren DR, Cooney JM, Jensen DJ, Wurms KV, Upritchard JE, Cannon RD, Wang MZ, Li MZ. Antifungal saponins from Paris polyphylla Smith. Planta med. 2008;74:1397-402.

18. Zhang XF, Cui Y, Huang JJ, Zhang YZ, Nie Z, Wang LF, Yan BZ, Tang YL, Liu Y. Immuno-stimulating properties of diosgenyl saponins isolated from Paris polyphylla. Bioorg Med Chem Lett. 2007;17:2408-13.

19. Negi JS, Bisht KB, Bhandari AK, Bhatt VP, Singh P, Singh N. Paris polyphylla: chemical and biological prospectives. Anticancer Agents Med Chem. 2014;14:833-9.

20. Wang Y, Gao W, Li X, Wei J, Jing S, Xiao P. Chemotaxonomic study of the genus Paris based on steroidal saponins. Biochem Syst Eco. 2013;48:163-73.

21. Tao Y, Huang S, Yan J, Cai B. Determination of major components from Radix Achyranthes bidentate using ultra high performance liquid chromatography with triple quadrupole tandem mass spectrometry and an evaluation of their anti-osteoporosis effect in vitro. J Sep Sci. 2019;42:221421. 
22. Zhao JY. Analysis on detoxification mechanism of processing Pinelliae Rhizoma with excipients. China New Medicine. 2004;3:90-1.

23. Yang L, Lin ZW. Study on the processing technology of Strychni Semen. Strait Pharm J. 2003;15:3940.

24. Anhui food and Drug Administration. Processing standard of Chinese Herbal Pieces in Anhui Province. Anhui. Anhui Science \& Technology Publishing House. 2005, P.147-148.

25. Ye YL. Preliminary study on processing of Colloid Paridis Rhizoma. Journal of Chinese Medicinal Materials.1991,14:35.

26. Nian SH, Liu EH, Fan Y, Alolga RN, Li HJ, Li P. Orthogonal separation protocol for the simultaneous preparation of four medically active compounds from Anemarrhenae Rhizoma by sequential polyamide and macroporous resin adsorbent chromatography. J Sep Sci. 2016;39:3195-204.

27. Fu SZ, Li N, Liu Z, Gao WY, Man SL. Determination of seven kinds of steroidal saponins in plants of Paris L. from different habitats by HPLC. Chin Tradit Herbal Drugs. 2012;43:2435-6.

28. Wen F, Yin H, Chen C, Liu X, Xue D, Chen T, He J, Zhang H. Chemical characteristics of saponins from Paris fargesii var. brevipetala and cytotoxic activity of its main ingredient, paris saponin $\mathrm{H}$. Fitoterapia. 2012;83:627-35.

29. Man S, Gao W, Zhang Y, Jin X, Ma C, Huang X, Li Q. Characterization of steroidal saponins in saponin extract from Paris polyphylla by liquid chromatography tandem multi-stage mass spectrometry. Anal Bioanal Chem. 2009;395:495-505.

30. Zhang Y, Yu L, Jin W, Li C, Wang Y, Wan H, Yang J. Simultaneous optimization of the ultrasonic extraction method and determination of the antioxidant activities of hydroxysafflor yellow $A$ and anhydrosafflor yellow B from safflower using a response surface methodology. Molecules 2020, 25, (5). doi:10.3390/molecules25051226.

31. Ferrone V, Todaro S, Carlucci M, FontanaA, Ventrella A, Carlucci G, Milanetti E. Optimization by response surface methodology of a dispersive magnetic solid phase extraction exploiting magnetic graphene nanocomposite coupled with UHPLC-PDA for simultaneous determination of new oral anticoagulants (NAOs) in human plasma. J Pharm Biomed Anal. 2020;179:112992. https://doi.org/10.1016/j.jpba.2019.112992.

32. Ji Y, Li X, Wang Z, Xiao W, He Z, Xiong Z, Zhao L. Extraction optimization of accelerated solvent extraction for eight active compounds from Yaobitong capsule using response surface methodology: Comparison with ultrasonic and reflux extraction. J Chromatogr A 2020, 460984. https://doi.org/10.1016/j.chroma.2020.460984.

33. Patel SB, Attar UA, Sakate DM, Ghane SG. Efficient extraction of cucurbitacins from Diplocyclos palmatus (L.) C. Jeffrey: Optimization using response surface methodology, extraction methods and study of some important bioactivities. Scientific reports 2020, 10, (1), 2109. https://doi.org/10.1038/s41598-020-58924-5.

34. Ahmad A, Alkharfy KM, Wani TA, Raish M. Application of Box-Behnken design for ultrasonic-assisted extraction of polysaccharides from paeonia emodi. Int J Biol Macromol. 2015;72:990-7. 
35. Thi NN, Lee YG, Seo KH, Kim HG, Lee DY, Baek NI. New furospirostane steroidal saponins from the flowers of Lilium Asiatic hybrids. Carbohyd Res. 2019;481:36-42.

36. Hwang JT, Park KS, Ryuk JA, Kim HJ, Ko BS. Development of an Oriental Medicine Discrimination Method through Analysis of Steroidal Saponins in Dioscorea nipponica Makino and Their AntiOsteosarcoma Effects. Molecules. 2019;24:4022. Doi:10.3390/molecules24224022.

37. Upadhyay S, Jeena GS, Shikha, Shukla RK. Recent advances in steroidal saponins biosynthesis and in vitro production. Planta. 2018;248:519-44.

38. Kentaro Inoue YE. Purification and characterization of furostanol glycoside 26-0-fl-glucosidase from Costus speciosus rhizomes. FEBS Lett. 1996;378:157-60.

39. Kang LP, Huang YY, Zhan ZL, Liu DH, Peng HS, Nan TG, Zhang Y, Hao QX, Tang JF, Zhu SD, et al. Structural characterization and discrimination of the Paris polyphylla var. yunnanensis and Paris vietnamensis based on metabolite profiling analysis. J Pharm Biomed Anal. 2017;142:252-61.

40. Kang LP, Yu K, Zhao Y, Liu YX, Yu HS, Pang X, Xiong CQ, Tan DW, Gao Y, Liu C, et al. Characterization of steroidal glycosides from the extract of Paris Polyphylla var. Yunnanensis by UPLC/Q-TOF MSE. J Pharm Biomed Anal. 2012;62:235-49.

41. Hong F, Jiang J, Liu X, Jiang H. Anticancer activity of Polyphyllin I in nasopharyngeal carcinoma by modulation of IncRNA ROR and P53 signaling. J Drug Target. 2019.

Doi:10.1080/1061186X.2018.1561887.

42. Yang $Q$, Chen $W, X u$ Y, Lv X, Zhang M, Jiang H. Polyphyllin I modulates MALAT1/STAT3 signaling to induce apoptosis in gefitinib-resistant non-small cell lung cancer. Toxicol Appl Pharm. 2018;356:1-7.

43. Chen M, Ye K, Zhang B, Xin Q, Li P, Kong AN, Wen X, Yang J. Paris Saponin II inhibits colorectal carcinogenesis by regulating mitochondrial fission and NF-kappaB pathway. Pharmacol Res. 2018;139:273-85.

44. Song YX, Ou YM, Zhou JY. Gracillin inhibits apoptosis and inflammation induced by lipopolysaccharide (LPS) to alleviate cardiac injury in mice via improving miR-29a. Biochem Bioph Res Co. 2020;523:580-7.

45. Zeng HQ, Yang LJ, Zhang XB, Chen Y, Cai JH. Dioscin prevents LPSinduced acute lung injury through inhibiting the TLR4/MyD88 signaling pathway via upregulation of HSP70. Mol Med Rep. 2018;17:6752-8.

46. Chen B, Zhou S, ZhanY, Ke J, Wang K, Liang Q, Hou Y, Zhu P, Ao W, Wei X, et al. Dioscin Inhibits the Invasion and Migration of Hepatocellular Carcinoma HepG2 Cell lines by Reversing TGF-beta1Induced Epithelial-Mesenchymal Transition. Molecules. 2019;24:2222.

Doi:10.3390/molecules24122222.

\section{Tables}

Table 1 Coded levels, conditions runs with the experimental used in BBD 


\begin{tabular}{lllll}
\hline Run & $\begin{array}{l}\text { Time } \\
(\mathrm{h}) \mathrm{X}_{1}\end{array}$ & $\begin{array}{l}\text { Concentration } \\
(\%) \mathrm{X}_{2}\end{array}$ & $\begin{array}{l}\text { Volume } \\
(\mathrm{mL}) \mathrm{X}_{3}\end{array}$ & $\begin{array}{l}\text { Yield of TSS } \\
(\mathrm{mg} / \mathrm{g}) \mathrm{Y}\end{array}$ \\
\hline 1 & $24(0)$ & $0.1(0)$ & $60(0)$ & 20.06 \\
2 & $24(0)$ & $0.1(0)$ & $60(0)$ & 19.73 \\
\hline 3 & $36(1)$ & $0.2(1)$ & $60(0)$ & 15.92 \\
\hline 4 & $24(0)$ & $0.2(1)$ & $90(1)$ & 18.62 \\
\hline 5 & $12(-1)$ & $0.1(0)$ & $90(1)$ & 16.86 \\
\hline 6 & $24(0)$ & $0.05(-1)$ & $30(-1)$ & 18.31 \\
\hline 7 & $36(1)$ & $0.1(0)$ & $30(-1)$ & 18.13 \\
\hline 8 & $24(0)$ & $0.1(0)$ & $60(0)$ & 19.89 \\
\hline 9 & $24(0)$ & $0.1(0)$ & $60(0)$ & 19.56 \\
\hline 10 & $12(-1)$ & $0.1(0)$ & $30(-1)$ & 15.66 \\
\hline 11 & $24(0)$ & $0.1(0)$ & $60(0)$ & 18.88 \\
\hline 12 & $12(-1)$ & $0.05(-1)$ & $60(0)$ & 16.79 \\
\hline 13 & $12(-1)$ & $0.2(1)$ & $60(0)$ & 15.12 \\
\hline 14 & $24(0)$ & $0.05(-1)$ & $90(1)$ & 15.69 \\
\hline 15 & $36(1)$ & $0.1(0)$ & $90(1)$ & 15.37 \\
\hline 16 & $36(1)$ & $0.05(-1)$ & $60(0)$ & 16.09 \\
\hline 17 & $24(0)$ & $0.2(1)$ & $30(-1)$ & 15.33 \\
\hline & & & & \\
\hline
\end{tabular}

Table 2. ANOVA for linear, square, and interactions of factors in RSM model for LCSS

\begin{tabular}{lllllll}
\hline Source & $\begin{array}{l}\text { Sum of } \\
\text { Squares }\end{array}$ & df & $\begin{array}{l}\text { Mean } \\
\text { Square }\end{array}$ & F Value & p-value & \\
\hline Model & 51.07 & 9 & 5.67 & 27.14 & 0.0001 & significant \\
$\mathrm{X}_{1}$-Time & 0.16 & 1 & 0.16 & 0.77 & 0.4084 & \\
\hline $\mathrm{X}_{2}$-Concentration & 1.46 & 1 & 1.46 & 6.96 & $0.0335^{*}$ & \\
\hline $\mathrm{X}_{3}$-Volume & 0.42 & 1 & 0.42 & 2.03 & 0.1972 \\
\hline $\mathrm{X}_{1} \mathrm{X}_{2}$ & 0.43 & 1 & 0.43 & 2.07 & 0.193 & \\
\hline $\mathrm{X}_{1} \mathrm{X}_{3}$ & 3.92 & 1 & 3.92 & 18.75 & $0.0034^{* *}$ & \\
\hline $\mathrm{X}_{2} \mathrm{X}_{3}$ & 9.35 & 1 & 9.35 & 44.69 & $0.0003^{* *}$ & \\
\hline $\mathrm{X}_{1}{ }^{2}$ & 17.92 & 1 & 17.92 & 85.72 & $<0.0001^{* *}$ & \\
\hline $\mathrm{X}_{2}{ }^{2}$ & 8.97 & 1 & 8.97 & 42.92 & $0.0003^{* *}$ & \\
\hline $\mathrm{X}_{3}{ }^{2}$ & 4.69 & 1 & 4.69 & 22.44 & $0.0021^{* *}$ & \\
\hline Residual & 1.46 & 7 & 0.21 & & & \\
\hline Lack of Fit & 0.63 & 3 & 0.21 & 1.02 & 0.4725 & not significant \\
\hline Pure Error & 0.83 & 4 & 0.21 & & & \\
\hline Cor Total & 52.53 & 16 & & & & \\
\hline $\mathrm{R}^{2}$ & 0.9721 & & & & & \\
\hline $\mathrm{R}^{2}$ Adj & 0.9363 & & & & & \\
\hline C.V. \% & 2.63 & & & & & \\
\hline
\end{tabular}

Table 3 Content of saponins in four batches of CPR and PPR (mg/g, $\mathrm{n}=3$ ) 


\begin{tabular}{cccccccc}
\hline \multicolumn{2}{c}{ program } & \multicolumn{5}{c}{ Content } \\
\cline { 2 - 7 } & & Polyphyllin VII & Polyphyllin II & Dioscin & Gracillin & Polyphyllin I & TSS \\
\hline Batch 1 & CPP & $1.07 \pm 0.03$ & $5.14 \pm 0.16$ & $0.76 \pm 0.06$ & $1.29 \pm 0.05$ & $8.39 \pm 0.37$ & $16.65 \pm 0.48$ \\
& PPP & $0.96 \pm 0.06$ & $12.57 \pm 0.41$ & $1.67 \pm 0.05$ & $2.88 \pm 0.06$ & $17.9 \pm 0.46$ & $35.97 \pm 0.96$ \\
\hline Batch 2 & CPP & $3.31 \pm 0.06$ & $4.30 \pm 0.07$ & $2.10 \pm 0.10$ & $0.76 \pm 0.02$ & $11.17 \pm 0.31$ & $21.63 \pm 0.24$ \\
\cline { 2 - 8 } & PPP & $2.41 \pm 0.04$ & $8.22 \pm 0.16$ & $1.90 \pm 0.07$ & $1.25 \pm 0.04$ & $16.27 \pm 0.36$ & $30.05 \pm 0.32$ \\
\hline Batch 3 & CPP & $0.96 \pm 0.07$ & $3.18 \pm 0.09$ & $1.19 \pm 0.02$ & $6.83 \pm 0.20$ & $9.86 \pm 0.31$ & $22.02 \pm 0.27$ \\
\cline { 2 - 7 } & PPP & $1.68 \pm 0.04$ & $5.31 \pm 0.09$ & $1.49 \pm 0.02$ & $14.88 \pm 0.29$ & $17.36 \pm 0.61$ & $40.72 \pm 0.57$ \\
\hline Batch 4 & CPP & $0.54 \pm 0.02$ & $3.25 \pm 0.08$ & $0.72 \pm 0.03$ & $4.09 \pm 0.08$ & $7.81 \pm 0.10$ & $16.39 \pm 0.23$ \\
\cline { 2 - 7 } & PPP & $0.62 \pm 0.02$ & $4.25 \pm 0.04$ & $0.97 \pm 0.04$ & $4.10 \pm 0.06$ & $10.31 \pm 0.15$ & $20.24 \pm 0.68$ \\
\hline
\end{tabular}

Figures 

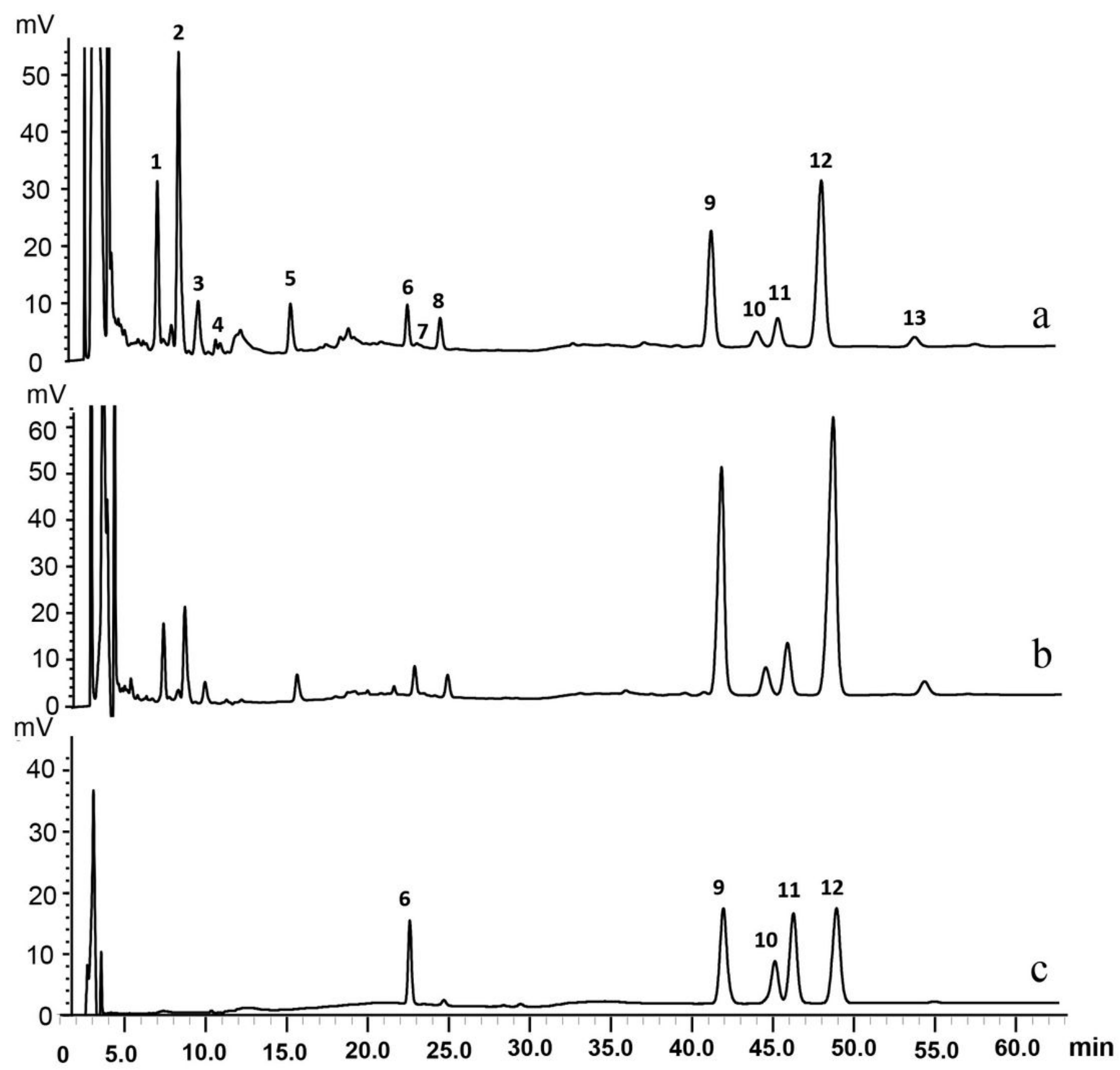

Figure 1

HPLC chromatograms of CPR (a), PPR (b) and five standards (c) peak 6, polyphyllin VIl; peak 9, peak polyphyllin II; peak 10, dioscin; peak11, gracillin; peak12, polyphyllin I. 
a

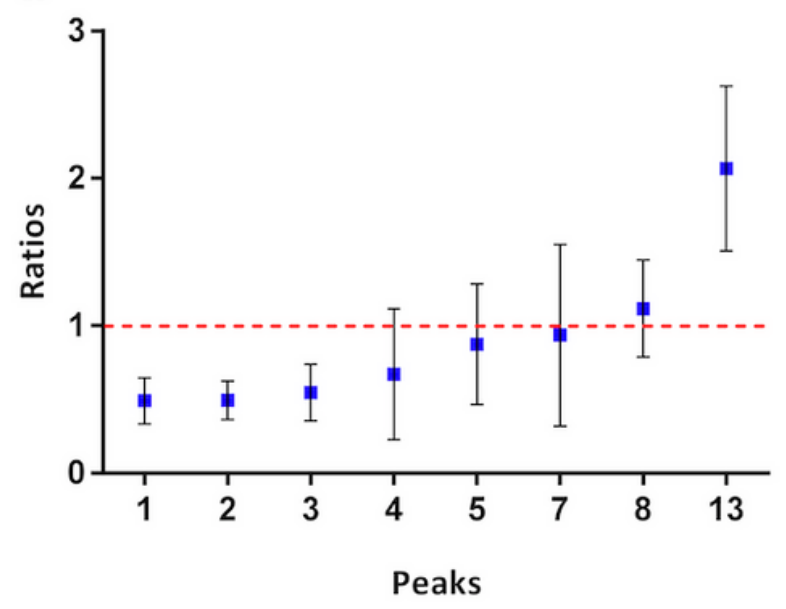

b

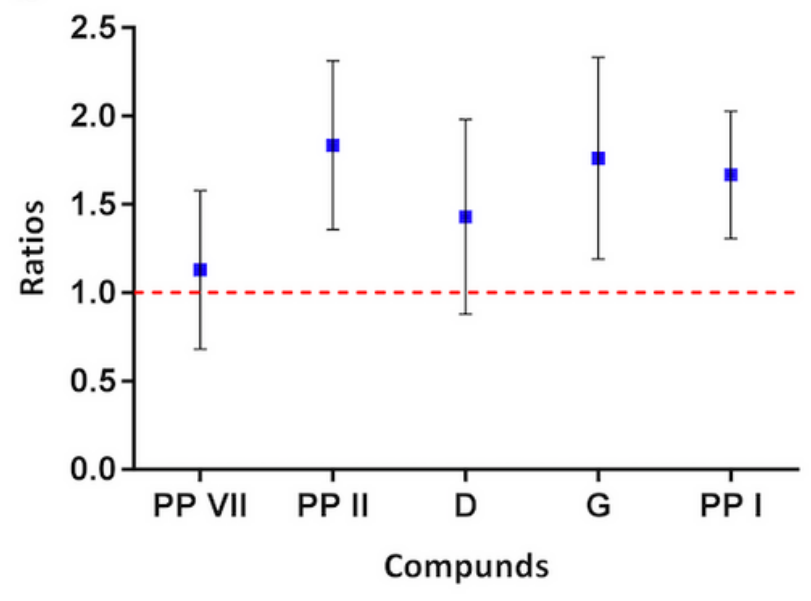

Figure 2

Ratios of area peak (a) and contents (b) of five saponins in four batches of PPR and CPR. PP VII, polyphyllin VII; PP II, polyphyllin II; G, gracillin; D, Dioscin; PP I, polyphyllin I. 

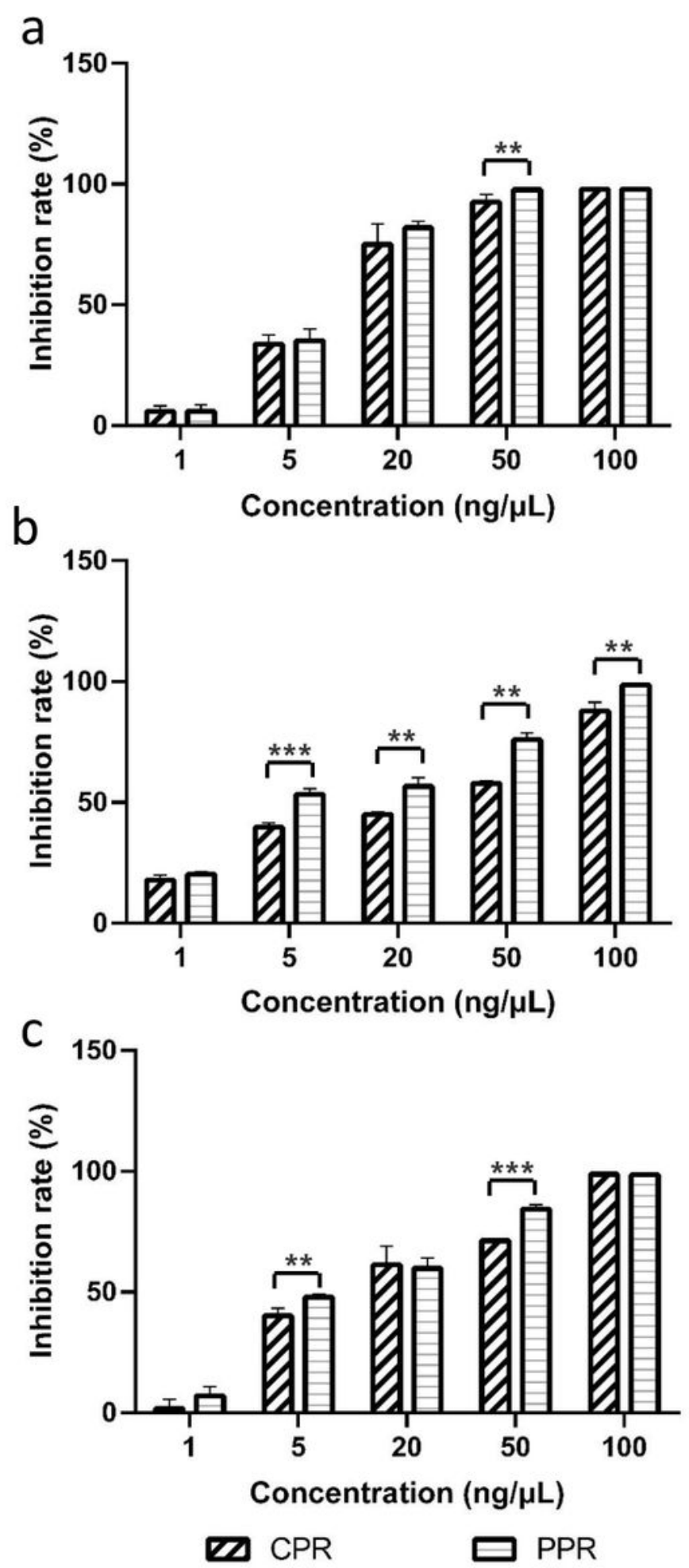

Figure 3

CPR and PPR inhibit the growth of H1299 (a), A549 (b) and HeLa (c) cell lines. "*” indicates the significance of difference of inhibition status between CPR and PPR at the same concentration. **, $p<0.01 ; * * *, p<0.001$. 

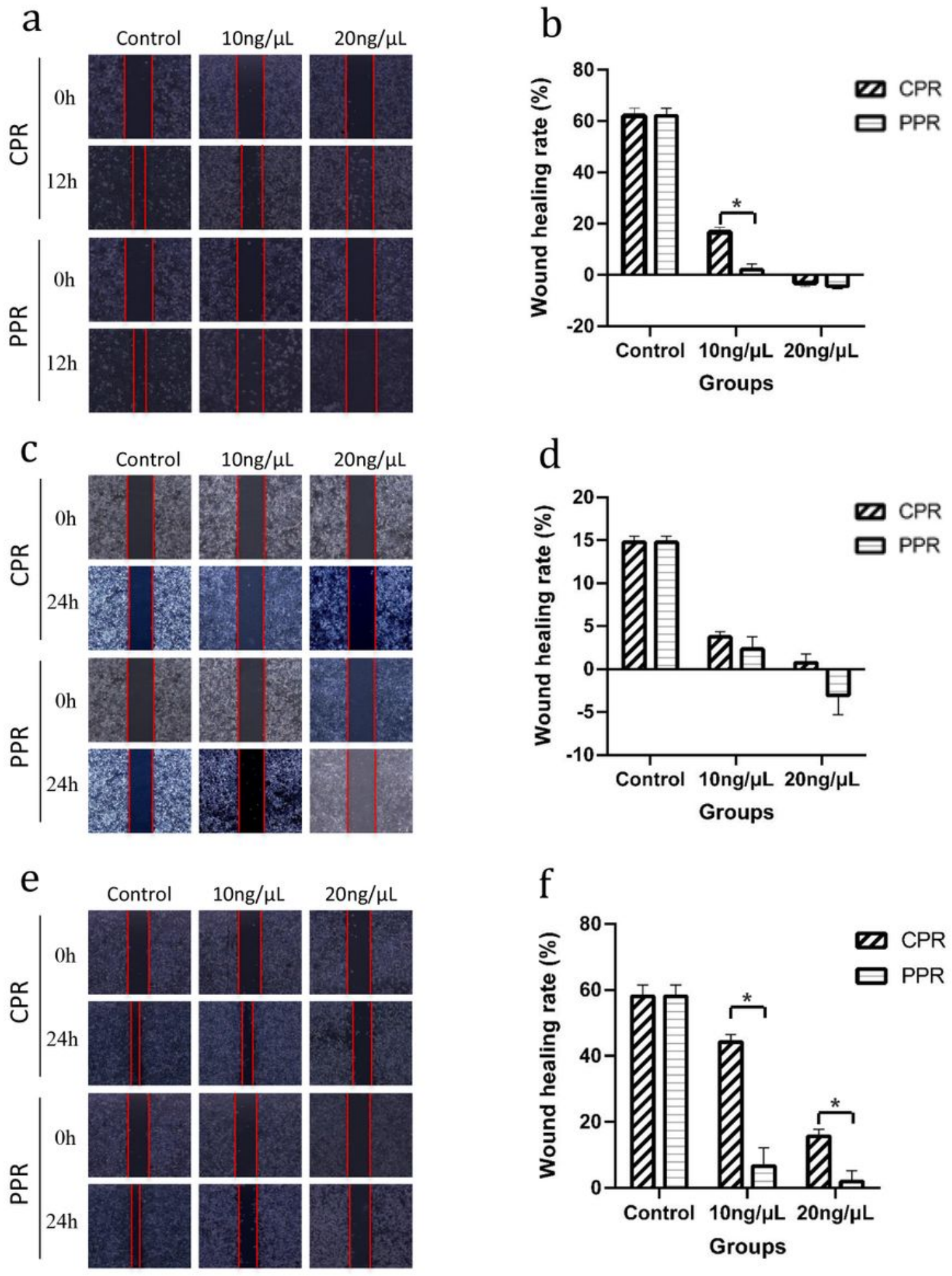

Figure 4

Effects of CPR and PPR on wound healing of H1299 (a, b), A549 (c, d) and HeLa (e, f) cell lines. "*” indicates the significance of difference of inhibition status between CPR and PPR at the same concentration. *, $p<0.05$. 


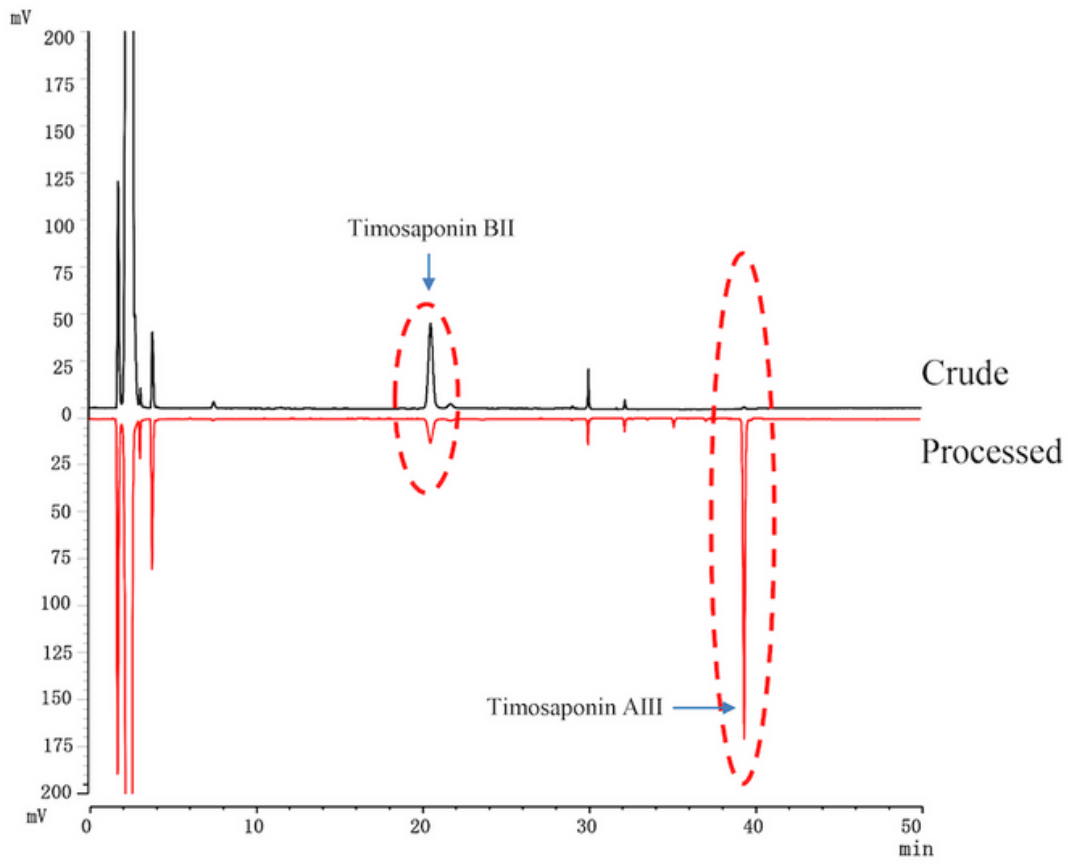

A

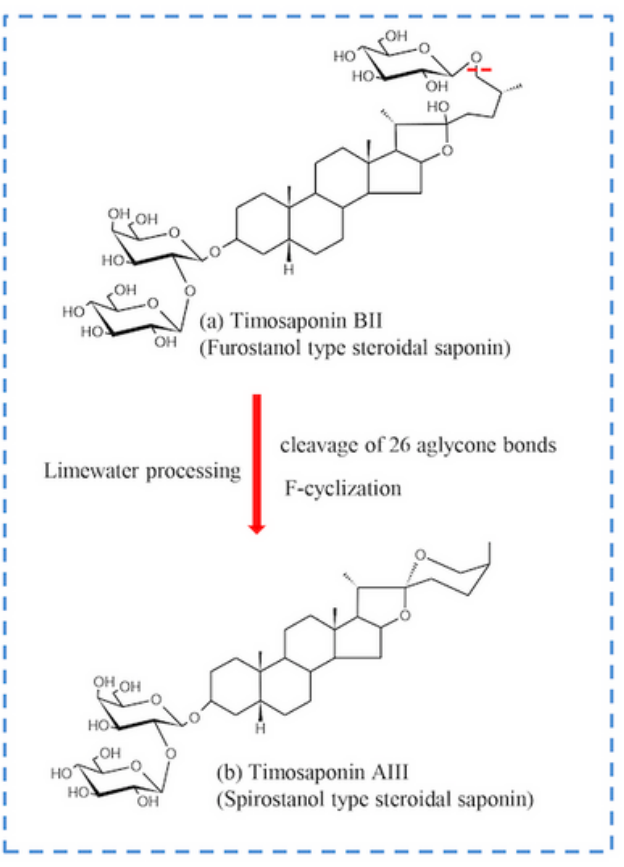

B

\section{Figure 5}

The transformation from TS Bll to TS Alll with cleavage of 26 aglycone bonds and F-cyclization processed by limewater. a, HPLC chromatograms of AR before and after processing; $b$, The transformation mechanism of furostanol saponins to spirostanol form.

\section{Supplementary Files}

This is a list of supplementary files associated with this preprint. Click to download.

- SupplementaryMaterial.docx 